\title{
Research Paper: Emotional Dysregulation Symptoms Based on Sensitivity to Punishment and Reward and Intensity Mediated by Emotion Regulation
}

\author{
Mitra Aghajani $^{1}$ (D), Mahshid Izadi ${ }^{*}$ (D), Noorali Farrokhi² (D), Fariba Hassani ${ }^{3}$ (i) \\ 1. Department of Education \& Counseling, Central Tehran Branch, Islamic Azad University, Tehran, Iran. \\ 2. Department of Education, Central Tehran Branch, Islamic Azad University, Tehran, Iran. \\ 3. Department of Assessment \& Measurement, Allameh Tabataba'i University, Tehran, Iran. \\ 4. Department of Psychology, Central Tehran Branch, Islamic Azad University, Tehran, Iran
}

\begin{tabular}{|c|c|}
\hline $\begin{array}{l}\text { Use your device to scan } \\
\text { and read the article online }\end{array}$ & dteation: Aghajani, M, Izadi, M., Farrokhi, N. A., Hassani, F. (2021). Emotional Dysregulation Symptoms Based on Sensitiv- \\
\hline 口ifing & $\begin{array}{l}\text { ity to Punishment and Reward and Intensity Mediated by Emotion Regulation. Journal of Practice in Clinical Psychology, } 9 \text { (1), } \\
\text { 153-164. https://doi.org/10.32598/jpcp.9.2.771.1 }\end{array}$ \\
\hline Dhting & dol'https://doi.org/10.32598/jpcp.9.2.771.1 \\
\hline
\end{tabular}

\section{(c) (1) (8)}

\section{Article info:}

Received: 15 Dec 2020

Accepted: 21 Feb 2021

Available Online: 01 Apr 2021

Keywords:

Motivation, Emotion

regulation, Emotion

disturbance, Students, Affective

Symptoms

\section{ABSTRACT}

Objective: The emotion dysregulation model by Mennin and Fresco considers the high comorbidity of generalized anxiety disorder and major depressive disorder and pays special attention to their comorbidity. Additionally, due to the high comorbidity of social anxiety disorder as well as anxiety and mood disorders, this disorder was considered along with the last two disorders. This study aimed to assess a Conceptual Model of Emotional Dysregulation Symptoms Based on Sensitivity to Punishment and Reward and Intensity of Positive and Negative Emotions Mediated by Emotion Regulation Strategies in Students.

Methods: 189 students studying at one of the public universities in Tehran were selected by random sampling method. Then, the Patient Health Questionnaire (PHQ-9), the Generalized Anxiety Disorder 7-item (GAD-7), the Social Interaction Anxiety Scale (SIAS), the Affect Intensity Measure (AIM), the Sensitivity to Punishment/Sensitivity to Reward Questionnaire (SPSRQ), the Difficulties in Emotion Regulation Scale (DERS), the Attention Control Scale (ATTC), the Experiences Questionnaire (EQ), the Emotion Regulation Questionnaire (ERQ), and the Responses to Positive Affect questionnaire (RPA) were distributed among them to collect the necessary data. The obtained data were analyzed by LISREL using structural equation modeling.

Results: Pearson correlation coefficient data indicated a significant relationship between motivation components, positive and negative emotion regulation strategies, and the symptoms of emotion dysregulation. The results showed that the conceptual model of the research fitted with the collected data; accordingly, the positive and negative strategies of emotion regulation mediated the relationship between motivation and the symptoms of emotion dysregulation.

Conclusion: The present research results supported the main hypothesis of the study. Thus, positive and negative emotion regulation strategies mediated the relationship between sensitivity to punishment and reward and the intensity of positive and negative emotion with

\section{"Corresponding Author:}

Mahshid Izadi, PhD.

Address: Department of Education, Central Tehran Branch, Islamic Azad University, Tehran, Iran.

Tel: +98 (912) 5088817

E-mail:drizadi.mahshid1452@gmail.com 


\section{Highlights}

- Reward and punishment sensitivity can lead to Positive and Negative emotions.

- The intensity of emotions can lead to Positive and Negative emotions.

- Positive and Negative emotions can lead to emotional dysregulation.

\section{Plain Language Summary}

This study was performed on 195 students of a university in Tehran. In general, the results showed that the intensity of negative and positive emotions as well as sensitivity to punishment and reward can lead to negative and positive emotions. Negative and positive emotions can also lead to emotional dysfunction, which in this study includes generalized anxiety disorder, social anxiety disorder, and depression.

\section{Introduction}

ue to the importance of Emotion Regulation (ER), theories were developed that emphasize the retention and social functions of emotions; the involvement of multiple biological systems in emotion production, and the dynamic model of emotion dysregulation aspects (Mennin \& Farach, 2007). The main models that currently explain the role of emotional dysregulation in various disorders are the modeler ones (Gross \& Jazaieri, 2014), including the emotion dysregulation model of Mennin and associates (Mennin \& Fresco, 2009; Mennin, Heimberg, Turk \& Fresco, 2002; Mennin, Holaway, Fresco, Moore \& Heimberg, 2007).

The emotion dysregulation model by Mennin, Heimberg, Turk, \& Fresco, (2002) considers the high comorbidity of Generalized Anxiety Disorder (GAD) and Major Depressive Disorder (MDD) (Newman, Przeworski, Fisher \& Borkovec 2010). They pay special attention to their comorbidity. Additionally, due to the high comorbidity of Social Anxiety Disorder (SAD) and other anxiety and mood disorders (Davidson, Hughes, George \& Blazer, 1993; Ohayon \& Schatzberg, 2010), SAD is also considered along with the last two disorders (Turk, Heimberg, Luterek, Mennin \& Fresco, 2005). To describe Mennin's model in detail, the common features of emotional problems symptoms must be considered in the Mennin model. Such conditions include repetitive or preservative negative thoughts. Besides, they may be used as a tool to cope with or compensate for perceived emotional experiences. Individuals with emotional symptoms may be more prepared to use repetitive cognitive strategies (e.g. worry, rumination); avoid or reduce irritability; degenerate immediate behavioral actions in response to their emotions at the cost of correct using of the motivational message it conveys to them; ultimately, lose the rich and fruitful aspect of life (Mennin \& Fresco, 2014).

Generally, according to Mennin et al.'s emotion dysregulation model (Mennin et al. 2002), 3 essential factors are proposed, including the following: motivational mechanisms, which indicate functional and leadership characteristics of a tendency to emotional response (the intensity of positive \& negative emotions \& sensitivity to punishment \& reward); regulatory mechanisms, which signify a change in response pathways to better match the necessities and restrictions, as well as personal values and goals (negative emotion regulation strategies; i.e., adaptive emotion regulation strategies), and contextual learning outcomes that reflect the development of flexible and extensive behavioral resources. Moreover, dysfunction in each of these systems facilitates the generation of various emotional symptoms (Mennin \& Fresco, 2014).

Emotion Regulation Strategies (ERSs) that have been widely discussed in studies (i.e., ERSs in Mennin's emotion dysregulation model) are based on negative emotions and responses to positive emotions. , The importance of this emotional experience has been extensively neglected. According to the broaden-and-build theory, positive emotions expand intellectual resources, reduce persistent emotional responses, lead to psychological flexibility and emotional wellbeing. Some positive ERSs are related to psychological pathology; one is positive emotion reduction and the other is rumination about positive emotion (Abasi Feldman, Farazmand, Pourshahbaz \& Sarichloo, 2018). In other words, in addition to negative ERSs, there exist positive ERSs. Besides, this 
conceptual model assumes that positive and negative ERSs play a mediating role in the relationship between sensitivity to punishment and reward and the intensity of negative emotion and emotional symptoms.

Emotional symptoms have high comorbidity. Furthermore, such high comorbidity is associated with greater inefficiency in individuals. Moreover, the complete emotion dysregulation model remains unexplored in a population with some emotional symptoms. Examining the fitness of this model in individuals with such symptoms provides evidence for the potential of the emotion dysregulation model being a transdiagnostic model. It also provides information on the mediating role of negative and positive ERSs. It also determines the most relevant strategies to each emotional symptom. In other words, not only the overall fit of the model in the symptoms of emotional disorders can be examined, but also the specific role of each of the negative and positive ERSs with each of the emotional symptoms can be studied. Additionally, the current study is the first attempt to evaluate the role of positive and negative ERSs, and the relationship between these strategies. It is also the first study to investigate the mediating role of positive ERSs in the relationship between reward and punishment sensitivity and the symptoms of emotional dysregulation. Besides, the current study findings not only add to the literature on ER, especially positive ERSs, but also if the model fits well enough in the population with emotional symptoms, they will present the possibility of being an effective ERSs improvement protocol to a range of emotional dysregulation symptoms.

Part of Mennin's emotion dysregulation model has been evaluated in various studies. Accordingly, it was indicated that this model explains ER difficulty in some emotional symptoms, including MDD, SAD, and GAD (Mennin \& Fresco, 2009; Mennin \& Fresco, 2014). According to studies, Mennin's model remains unexamined in subjects with emotional symptoms. Thus, this is the first attempt in this respect. Moreover, due to the significance of positive ERSs in the etiology of emotional symptoms and the transdiagnosis nature of this component (Carl, Gallagher \& Barlow, 2018), it has been added to the present research model. The present study is the first attempt to derivative Mennin's emotion dysregulation model. To expand this model, it seeks to investigate whether or not the conceptual model of emotional dysregulation symptoms fits based on sensitivity to punishment and reward and the intensity of positive and negative emotions with the mediation of positive and negative ERSs in students.

\section{Materials and Methods}

The current cross-sectional study applied structural equation modeling. The statistical population of the present study consisted of all $\geq 18$-year-old students at one of the public universities in Tehran. To determine the sample size, an essential question in structural equation modeling is to determine the minimum sample size required to collect the relevant data. Kline believes that in exploratory factor analysis, 5 to 25 samples are required per variable; however, the minimum sample size of 200 is defensible. According to Kline, the sample size required for this study ranged between 65 and 325 subjects according to the number of 13 variables (Kline, 2015: 23). The minimum sample size for structural equations should be from 200 to 250 subjects; therefore, 200 students from one of the public universities in Tehran were randomly selected to participate in this research. The following tools were employed in the present study:

\section{The Patient Health Questionnaire (PHQ-9)}

This questionnaire is a self-report tool that assesses the severity of depression. It is scored on a Likert-type scale, ranging from 0 (never) to 3 (almost every day). The English version of PHQ-9 has acceptable validity and reliability. It also consists of $88 \%$ sensitivity and $88 \%$ specificity for diagnosing depression. Scores of 5, 10, 15, and 20 indicate mild, moderate, moderately severe, and severe depression, respectively (Kroenke, Spitzer \& Williams, 2001). The validity of this scale on diabetic patients in Iran has been reported as acceptable (Khamseh et al., 2011).

\section{Generalized Anxiety Disorder 7-item (GAD-7)}

This questionnaire was developed by Spitzer, Kroenke, Williams \& Löwe (2006) to diagnose and assess the severity of GAD. This scale has 7 questions and another question that measures the degree of disorder involvement in patients' individual, social, familial, and occupational functions. This scale is a 4-statement questionnaire, i.e., scored on a scale from 0 to 3 . Its internal validity and test-retest reliability were reported to be 0.92 and 0.83 , respectively. The internal validity of the Iranian version of the questionnaire was measured to be 0.85 (Naeinian Shaeiri, Sharif \& Hadian, 2011).

\section{Social Interaction Anxiety Scale (SIAS)}

This scale was developed by Mattick \& Christopher (1998). This 20-item self-report tool is scored on a 5-point Likert-type scale. Its Cronbach's alpha coeffi- 
cient was reported as $0.85-0.90$ and its test-retest reliability was reported to be 0.86 in the 2 -week interval (Mattick \& Christopher Clarke, 1998). The correlation of this scale with other scales of social interaction fear, avoidance of social situations, and other tools that assess social anxiety has been computed as moderate to high (Rodebaugh, Woods \& Heimberg, 2007). In Iran, Cronbach's alpha coefficient and test-retest reliability of this tool were reported to be 0.90 and 0.79 , respectively (Tavoli et al., 2012). This scale was used to measure the severity of SAD symptoms. The internal consistency of the Persian version of this tool was calculated as 0.91 . Additionally, confirmatory factor analysis data revealed that the factor structure of this scale was valid: $\mathrm{RMSEA}=0.04, \mathrm{GFI}=0.94, \mathrm{P}<0.001, \mathrm{df}=149, \chi^{2}=297.43$ (Abasi, Mohammadkhani, Pourshahbaz \& Dolatshahi, 2017).

\section{Affect Intensity Measure (AIM)}

This scale was developed by Larsen et al. in Larsen \& Diener (1987). This is a 40-question self-report scale that assesses individual differences in affect intensity. The Cronbach's alpha coefficient has been reported for this scale to range between 0.90 and 0.94 in 4 different samples. Larsen et al. reported Cronbach's alpha coefficient, parental report, and two-week test-retest reliability of this scale to be $0.81,0.50$, and 0.61 , respectively. Friends' reports on mood were also reported to be 0.41 (Larsen \& Diener, 1987). In Iran, Cronbach's alpha coefficient of this scale was reported to be 0.83 . Furthermore, friends ' reports on mood and parents' reports on mood and reliability of the scale for two weeks were $0.39,0.47$, and 0.56, respectively (Golparvar, Javadian $\&$ Barazandeh, 2015). The negative emotion intensity subscale (11 questions) was used to measure the intensity of negative emotion as one of the latent variables of motivation in this study. The internal consistency of the Persian version of the questionnaire was equal to 0.88 (Abasi et al., 2017). Moreover, confirmatory factor analysis computed by Abasi et al. (2017) indicated that the one-factor structure of this scale is valid; $\mathrm{RMSEA}=0.04$, $\mathrm{GFI}=0.95, \mathrm{P}<0.001, \mathrm{df}=270, \chi^{2}=535.94$.

\section{Sensitivity to Punishment and Sensitivity to Re- ward Questionnaire (SPSRQ)}

This questionnaire was first developed by Torrubia \& Tobeña (1984); it measures individual differences in sensitivity to reward and punishment in individuals. It is a 48-item self-report questionnaire. In this questionnaire, the reporter obtains a score between 1 and 2 per item. Besides, the total score ranges between 48 and 96 .
Cronbach's alpha coefficient of this questionnaire for the subscales of reward sensitivity and punishment sensitivity was reported to be 0.76 and 0.82 , respectively. An agreement coefficient of $81 \%$ has also been reported for this questionnaire (Torrubia \& Tobeña, 1984). Sajjadi also reported the reliability coefficient of the subscales of punishment sensitivity and reward sensitivity to be 0.74 and 0.70 , respectively (quoted by Goodarzi \& Shameli, 2011). To measure the components of reward sensitivity and punishment sensitivity, the latent variable of motivation was used in this scale. The internal consistency of the subscales of safety and reward motivation in its Persian version were 0.74 and 0.84 , respectively. Confirmatory factor analysis data also indicated that the reward and safety subscales were valid as follows, respectively: $\mathrm{RMSEA}=0.03$, $\mathrm{GFI}=0.96, \mathrm{P}<0.001, \mathrm{df}=128$, $\chi^{2}=196.62$ and $\mathrm{RMSEA}=0.007, \mathrm{GFI}=0.96, \mathrm{P}>0.376$, $\mathrm{df}=219, \chi^{2}=225.20$ (Abasi et al., 2017).

\section{Emotion Regulation Difficulty Scale}

This scale was developed in 2004 by Gratz \& Roemer (2004). The DERS is a 36-item self-report scale that assesses individuals' ERSs and consists of 6 subscales. These subscales include the nonacceptance of emotional responses, difficulties engaging in goal-directed behavior, impulse control difficulties, the lack of emotional awareness, limited access to ERSs, and the lack of emotional clarity. The psychometric properties of the main version of this scale are as follows: This scale has good internal consistency (0.93); the reliability of its subscales, using Cronbach's alpha coefficient was computed to be $>0.80$, i.e., highly suitable for any subscale (Gratz \& Roemer, 2004). The psychometric properties of the DERS's Persian version are as follows: Its reliability was obtained by Cronbach's alpha coefficient and splithalf methods to be 0.86 and 0.80 , respectively. To determine the validity of the scale, its score was correlated with the score of the Zuckerman Emotion Questionnaire; accordingly, there was a positive significant correlation between them $(\mathrm{P}<0.043 \& \mathrm{r}=0.26, \mathrm{~N}=59)$. This finding indicates that the DERS has the necessary validity. The internal consistency of the acceptance subscale of its Persian version equaled 0.85 . Confirmatory factor analysis data also suggested that this subscale has appropriate structural validity; $\mathrm{RMSEA}=0.05$, GFI $=0.99, \mathrm{P}<0.05$, $\mathrm{df}=4, \chi^{2}=9.15$ (Abasi et al., 2017). The acceptance subscale of the DERS was used in the current research.

\section{Attention Control Scale (ATTC)}

This scale was first developed and used by Derryberry \& Reed (2002). It is a 20-item scale. In factor analysis 
conducted by Derryberry \& Reed (2002), 3 factors were identified, as follows: attention change, attention focus, the ability of mental flexibility. In this study, this scale's Cronbach's alpha coefficient was reported to be 0.88 . Derryberry \& Reed (2002) also indicated that attention control is inversely related to state anxiety. In another study, Cronbach's alpha coefficient of the total scale and the subscales of concentration and attention change were calculated as $0.84,0.82$, and 0.68 respectively (Ólafsson et al., 2011). The reliability of retesting the subscales of concentration and attention change was 0.80 and 0.76 , respectively. This questionnaire was used to evaluate one of the variables of the emotion regulation strategy of a presence called attention control (Abasi et al., 2017).

\section{Experiences Questionnaire (EQ)}

This questionnaire was developed in 2007 by Fresco et al. (2007). The EQ is a 20-item self-report questionnaire that measures decentering and non-assimilation from negative thinking content, i.e., the process of change in Mindfulness-Based Cognitive Therapy (MBCT). Items are graded on a 5-point Likert-type scale, ranging from 0 (never) to 5 (all the time). This questionnaire included two factors of decentering and rumination; their internal consistency was reported to be 0.83 and 0.70 , respectively, using Cronbach's alpha coefficient. Besides, the EQ reported acceptable convergent and divergent correlations in the general and clinical population samples (Fresco et al., 2007). The psychometric properties of the Persian version of this questionnaire are as follows: Cronbach's alpha coefficient of the decentering subscale was measured as 0.82 . Additionally, a negative relationship was found between the decentering subscale and depression symptoms, rumination, depression, experiential avoidance, and ER (Taherifar, Ferdowsi, Mootabi, Mazaheri \& Fata, 2016). In this study, the decentering subscale (11 questions) was used to evaluate the ERS of decentering.

\section{Emotion Regulation Questionnaire (ERQ)}

It is a self-report questionnaire and consists of 10 items. The ERQ was developed by Gross and John in Gross \& John (2003) and measures 2 ERSs of suppression and reappraisal. The reappraisal subscale consists of 6 items (e.g. I change my emotions by changing the way I think about the situation). Moreover, the suppression subscale consists of 4 items (e.g. I do not express negative emotions when I experience them). Respondents are requested to rate their answers on a scale of 1 (high disagreement) to 7 (high agreement). This questionnaire signified good internal reliability (reappraisal: $0.79 \&$ suppres- sion: 0.73 ) as well as good convergent validity (Gross \& John, 2003). In the Italian version of the questionnaire, internal consistency for the subscale of reappraisal and suppression was obtained as 0.84 and 0.72 , respectively. Furthermore, the test-retest reliability of a -month interval of the two subscales was reported to be 0.67 and 0.71, respectively (Balzarotti, John \& Gross, 2010). Mahmoud Alilou, Ghasempour, Azimi, Akbari \& Fahimi (2012) reported Cronbach's alpha coefficient for the whole questionnaire and the subscales of reappraisal and suppression to be $0.71,0.73$, and 0.52 , respectively. The reappraisal subscale was used to assess the re-framing ERS. The internal consistency of the Persian version of the re-evaluation subscale was equal to 0.81 . In addition, confirmatory factor analysis data revealed that the onefactor structure of this subscale is valid; RMSEA $=0.05$, $\mathrm{GFI}=0.99, \mathrm{P}<0.01, \mathrm{df}=5, \chi^{2}=13.86$ (Abasi et al., 2017). The reappraisal subscale was used in the study.

\section{Responses to Positive Affect questionnaire (RPA)}

This tool was developed by Feldman, Joormann \& Johnson (2008) to assess the response to positive emotion. This 17-item questionnaire is answered on a Likerttype scale, ranging from 1 (almost never) to 4 (almost always). In the initial scale, 3 factors, including emotionbased, positive emotion, and self-focused emotion suppression were obtained. Furthermore, the internal validity of the 3 factors was reported to be $0.76,0.79$, and 0.73 , respectively. Abasi et al. (2018) explored the validity and reliability of this questionnaire in Iran. Exploratory factor analysis data yielded two subscales of rumination on positive emotion and suppression of positive emotion. Confirmatory factor analysis data demonstrated model fit $\left(\chi^{2}=135.51, \mathrm{df}=82, \chi^{2} / \mathrm{df}=1.65, \mathrm{P}<0.001, \mathrm{CFI}=0.98\right.$, $\mathrm{GFI}=0.97$, RMSEA $=0.03$ ), and the internal validity of the two subscales to the results were computed as 0.87 and 0.77 , respectively.

Two hundred at one of the public universities in Tehran students were randomly selected to fill the demographic data questionnaire, the PHQ-9, GAD-7, SIAS, AIM, SPSRQ, DERS, ATTC, EQ, ERQ, and RPA. They were also requested to mention their e-mail ID in the questionnaire if requesting the relevant results. The inclusion criteria of the study consist of students aged $\geq 18$ to 50 years, studying at one of the public universities in Tehran, and providing an informed consent form along with completing the questionnaire battery. Distorted questionnaires or incomplete answers to them were also the exclusion criteria of this research. 


\section{Data analysis}

Pearson product-moment correlation coefficient and structural equation modeling were implemented to analyze the obtained data. For Pearson product-moment correlation coefficient, SPSS software v. 25 was used. Besides, structural equation modeling was analyzed and reported using LISREL software v. 8.8. To estimate the parameters, the maximum likelihood estimation method was used. To evaluate the model fit of Chi-squared index, Root Mean Square Error of Approximation (RMSEA), Standard Root Mean Square Residual (SRMR), Goodness of I (GFI), Comparative Fit Index (CFI), Normal Fit Index (NFI), and Incremental Fit Index (IFI) were applied.

\section{Results}

The study participants were 189 subjects; of them, 96 $(50.79 \%)$ were female and $93(49.20 \%)$ were male. Additionally, 30 (15.87\%) of them were married and 153 $(84.12 \%)$ were single. The explored students aged between 18 and 35 years. Moreover, students with undergraduate education constituted the largest proportion of participants in this study. The Mean \pm SD age of the study subjects was $23.97 \pm 3.1$ years. The demographic characteristics of the study participants are presented in Table 1.

The Mean \pm SD and correlation matrix of research variables are reported in Table 2. Correlation results indicated that positive emotion intensity, negative emotion intensity, and reward sensitivity were significantly and negatively correlated with social anxiety, generalized anxiety, and depression. Furthermore, punishment sensitivity presented a significant positive relationship with the variables of social anxiety, generalized anxiety, and depression. Reappraisal ERS, attention ERS, acceptance ERS, positive emotion reduction ERS, positive rumination ERS, and positive suppression ERS also were significantly and adversely correlated with social anxiety, generalized anxiety, and depression.

Additionally, the measurement model for the PHQ-9, GAD-7, SIAS, AIM, SPSRQ, DERS, ATTC, EQ, ERQ, and RPA were evaluated; accordingly, the relevant results indicated a good fit of the measurement model of each scale. Then the conceptual model was measured, and the fitness indices reported in Table 3 indicated the appropriate fitness of the data with the conceptual model.

As per Table 4 and Figure 1, motivation, as a predictor variable with standard coefficients of 0.84 and 0.95 influences positive ERS and negative ERS, respectively. Moreover, positive ERSs with a coefficient of -0.32 and negative ERSs with a coefficient of -0.70 influenced emotion dysregulation symptoms; all coefficients were significant at the level of 0.001 . Furthermore, the indirect effect of motivation on emotion dysregulation symptoms was measured as -0.41 , i.e., significant at the level of 0.001 .

\section{Discussion}

The present study findings indicated that the conceptual model of emotion dysregulation symptoms adequately fits based on punishment sensitivity and reward sensitivity and the intensity of positive and negative emotions mediated by ERSs in students. Based on studies, this was the first comprehensive study to evaluate a complete Mennin's ER model.

The obtained data were consistent with those of numerous studies on the mediation of ERSs in the relationship

Table 1. The study participants' demographic characteristics

\begin{tabular}{|c|c|c|c|c|c|}
\hline \multicolumn{2}{|c|}{ Demographic Characteristics } & \multirow{2}{*}{$\begin{array}{c}\mathbf{N}(\%) \\
96(8.50) 96\end{array}$} & \multicolumn{2}{|c|}{ Demographic Characteristics } & \multirow{2}{*}{$\begin{array}{c}\mathbf{N}(\%) \\
92(48.7)\end{array}$} \\
\hline & Female & & & BA & \\
\hline \multirow[t]{4}{*}{ Gender } & Male & $93(49.2) 93$ & Education level & $\mathrm{MA}$ & $70(37.0)$ \\
\hline & Total & $189(100)$ & & PhD & $27(14.3)$ \\
\hline & Single & $153(81.0)$ & & $>20$ & $15(7.9)$ \\
\hline & Married & 30 (15.9) & & $20-25$ & $119(63.0)$ \\
\hline \multirow[t]{3}{*}{ Marital status } & & & Age (year) & & \\
\hline & Divorced & $3(1.6)$ & & $25-30$ & $52(27.5)$ \\
\hline & Other & $3(1.6)$ & & $30-35$ & $3(1.6)$ \\
\hline
\end{tabular}


Table 2. Correlation matrix, mean, and standard deviation values of the research variables $(\mathrm{N}=189)$

\begin{tabular}{|c|c|c|c|c|c|c|c|}
\hline Variable & Mean士SD & \multirow[t]{2}{*}{1} & \multirow[t]{2}{*}{2} & \multicolumn{2}{|l|}{3} & \multirow[t]{2}{*}{4} & \multirow[t]{2}{*}{5} \\
\hline 1. Positive Emotion Intensity & $44.61 \pm 7.57$ & & & & & & \\
\hline 2. Negative Emotion Intensity & $19.22 \pm 9.84$ & $0.59^{* *}$ & & & & & \\
\hline 3. Reward Sensitivity & $11.94 \pm 4.59$ & $0.65^{* *}$ & $0.56^{* *}$ & & & & \\
\hline 4. Punishment Sensitivity & $11.17 \pm 6.23$ & $-0.64^{* *}$ & $-0.73^{* *}$ & \multicolumn{2}{|c|}{$-0.64^{* *}$} & & \\
\hline 5. Reappraisal Emotion Regulation Strategy & $25.13 \pm 9.03$ & $0.77^{* *}$ & $0.59^{* *}$ & \multicolumn{2}{|c|}{$0.53^{* *}$} & $-0.55^{* *}$ & \\
\hline 6. Attention Emotion Regulation Strategy & $17.87 \pm 8.15$ & $0.78^{* *}$ & $0.53^{* *}$ & \multicolumn{2}{|c|}{$0.70^{* *}$} & $-0.57^{* *}$ & $0.67^{* *}$ \\
\hline 7. Acceptance Emotion Regulation Strategy & $12.47 \pm 4.74$ & $0.76^{* *}$ & $0.45^{* *}$ & \multicolumn{2}{|c|}{$0.61^{* *}$} & $-0.51^{* *}$ & $0.61^{* *}$ \\
\hline 8. Positive Emotion Reduction Emotion Regulation Strategy & $11.83 \pm 3.41$ & $0.60^{* *}$ & $0.62^{* *}$ & \multicolumn{2}{|c|}{$0.46^{* *}$} & $-0.61^{* *}$ & $0.43^{* *}$ \\
\hline 9. Positive Rumination Emotion Regulation Strategy & $11.83 \pm 3.24$ & $0.71^{* *}$ & $0.49^{* *}$ & \multicolumn{2}{|c|}{$0.48^{* *}$} & $-0.46^{* *}$ & $0.57^{* *}$ \\
\hline 10. Positive Suppression Emotion Regulation Strategy & $17.61 \pm 6.23$ & $0.67^{* *}$ & $0.50^{* *}$ & \multicolumn{2}{|c|}{$0.65^{* *}$} & $-0.49^{* *}$ & $0.56^{* *}$ \\
\hline 11. Social Anxiety & $27.18 \pm 12.18$ & $-0.67^{* *}$ & $-0.45^{* *}$ & \multicolumn{2}{|c|}{$-0.57^{* *}$} & $0.51^{* *}$ & $-0.60^{* *}$ \\
\hline 12. Generalized Anxiety & $10.97 \pm 5.67$ & -0.64 & $-0.48^{* *}$ & \multicolumn{2}{|c|}{$-0.60^{* *}$} & $0.51^{* *}$ & $-0.61^{* *}$ \\
\hline 13. Depression & $12.05 \pm 7.69$ & -0.68 & $-0.49^{* *}$ & \multicolumn{2}{|c|}{$-0.61^{* *}$} & $0.53^{* *}$ & $-0.59^{* *}$ \\
\hline Variable & 6 & 7 & 8 & 9 & 10 & 11 & 12 \\
\hline \multicolumn{8}{|l|}{ 1. Positive Emotion Intensity } \\
\hline \multicolumn{8}{|l|}{ 2. Negative Emotion Intensity } \\
\hline \multicolumn{8}{|l|}{ 3. Reward Sensitivity } \\
\hline \multicolumn{8}{|l|}{ 4. Punishment Sensitivity } \\
\hline \multicolumn{8}{|l|}{ 5. Reappraisal Emotion Regulation Strategy } \\
\hline \multicolumn{8}{|l|}{ 6. Attention Emotion Regulation Strategy } \\
\hline 7. Acceptance Emotion Regulation Strategy & $0.74^{* *}$ & & & & & & \\
\hline 8. Positive Emotion Reduction Emotion Regulation Strategy & $0.46^{* *}$ & $0.49^{* *}$ & & & & & \\
\hline 9. Positive Rumination Emotion Regulation Strategy & $0.43^{* *}$ & $0.53^{* *}$ & $0.70^{* *}$ & & & & \\
\hline 10. Positive Suppression Emotion Regulation Strategy & $0.70^{* *}$ & $0.58^{* *}$ & $0.48^{* *}$ & $0.49^{* *}$ & & & \\
\hline 11. Social Anxiety & $-0.69^{* *}$ & $-0.65^{* *}$ & $-0.54^{* *}$ & $-0.58^{* *}$ & $-0.60^{* *}$ & & \\
\hline 12. Generalized Anxiety & $-0.76^{* *}$ & $-0.59^{* *}$ & $-0.39^{* *}$ & $-0.40^{* *}$ & $-0.69^{* *}$ & $0.63^{* *}$ & \\
\hline 13. Depression & $0.72^{* *}$ & $-0.64^{* *}$ & $0.49^{* *}$ & $-0.53^{* *}$ & $-0.63^{* *}$ & $0.73^{* *}$ & $0.83^{* *}$ \\
\hline
\end{tabular}


Table 3. The fitness index of the conceptual model of the research

\begin{tabular}{|c|c|c|c|c|c|c|c|c|}
\hline Chi-Squared & df & GFI & AGFI & CFI & RMSEA & NFI & IFI & SRMR \\
\hline 133.26 & 56 & 0.93 & 0.89 & 0.96 & 0.086 & 0.97 & 0.97 & 0.055 \\
\hline
\end{tabular}

between the intensity of emotions and reinforcement and punishment sensitivity, and psychopathological symptoms. Dennis (2007) argued that low reward sensitivity leads to depression only in certain circumstances (i.e., with a low reappraisal strategy). Wang et al. (2019) reported that reinterpretation, a reassessment strategy, reduces the effect of low BAS sensitivity on the depression and Post-Traumatic Stress Disorder (PTSD) symptoms. Besides, immersion in emotion intensifies the effect of BAS and BIS on the symptoms of depression and PTSD. Markarian, Pickett, Deveson \& Kanona (2013) also documented that BIS and BAS present no direct effect on anxiety; however, they do affect it through the mediation of ER difficulty. We also detected that the combination of a negative emotional reaction and a reduced reward response increases ER difficulty; consequently, it leads to the symptoms of anxiety, depression, and stress. These findings were also consistent with those of studies suggesting that life events and childhood traumas lead to pathological symptoms, such as depression, anxiety, and other disorders through dysfunctional cognitive ERSs (e.g. Huh, Kim, Lee \& Chae, 2017).

Two previous studies examined the almost complete Mennin's ER model; the obtained data were in line with those of the present study. In the first study, Taherifar et al. (2016) concluded that ERSs mediate the relationship between negative emotion intensity and the immune mo- tivation system, and generalized anxiety disorder symptoms. In addition to physical awareness and re-framing, attention control strategies allowing and decentering mediated the relationship between the intensity of negative emotion and punishment sensitivity, and anxiety symptoms. Abbasi et al. (Abasi, Pourshahbaz, Mohammadkhani \& Dolatshahi, 2017) also supported Mennin's model. In this study, ERSs (attention control, decentering, re-appraisal, allowing) mediated the relationship between motivation (Punishment \& reward) and emotion dysregulation symptoms (worry \& social anxiety). In their study, unlike the present study, the fit of the model significantly improved after eliminating the emotional intensity. Abbasi et al. (Abasi et al., 2017) explained that emotional intensity is common between mood and anxiety disorders; however, it is more related to MDD and GAD than SAD.

In the present study, the relationship between negative ERSs (reappraisal, decentering, \& attention control) and psychopathological symptoms was much stronger than that between positive ERSs (Positive emotion rumination \& reduction) and psychopathological symptoms. This is probably because mood and anxiety disorders, such as GAD and MDD are further associated with negative emotions than positive emotions; however, pathologies, such as substance dependence and gambling are more associated with positive emotions (Ciccarelli,

Table 4. Standardized, direct, indirect, and total coefficients in the conceptual model of the research

\begin{tabular}{|c|c|c|c|c|c|}
\hline Criterion Variables & Predictive Variables & Direct Effect & Indirect Effect & Total Effect & Explained Variance \\
\hline \multirow[t]{4}{*}{$\begin{array}{l}\text { On The Emotion Dysregula- } \\
\text { tion Symptoms From: }\end{array}$} & & & & & 0.68 \\
\hline & $\begin{array}{l}\text { Negative Emotion Regula- } \\
\text { tion Strategies }\end{array}$ & $-0.70^{*}$ & - & $-0.70^{*}$ & \\
\hline & $\begin{array}{l}\text { Positive Emotion Regula- } \\
\text { tion Strategies }\end{array}$ & $-0.32^{*}$ & - & $-0.32^{*}$ & \\
\hline & Motivation & - & $-0.41^{*}$ & $-0.41^{*}$ & \\
\hline \multirow[t]{2}{*}{$\begin{array}{l}\text { On Negative Emotion Regu- } \\
\text { lation Strategies From: }\end{array}$} & & & & & 0.48 \\
\hline & Motivation & $0.95^{*}$ & - & $0.95^{*}$ & \\
\hline \multirow[t]{2}{*}{$\begin{array}{l}\text { On Positive Emotion Regula- } \\
\text { tion Strategies From: }\end{array}$} & & & & & 0.47 \\
\hline & Motivation & $0.84^{*}$ & - & $0.84^{*}$ & \\
\hline
\end{tabular}




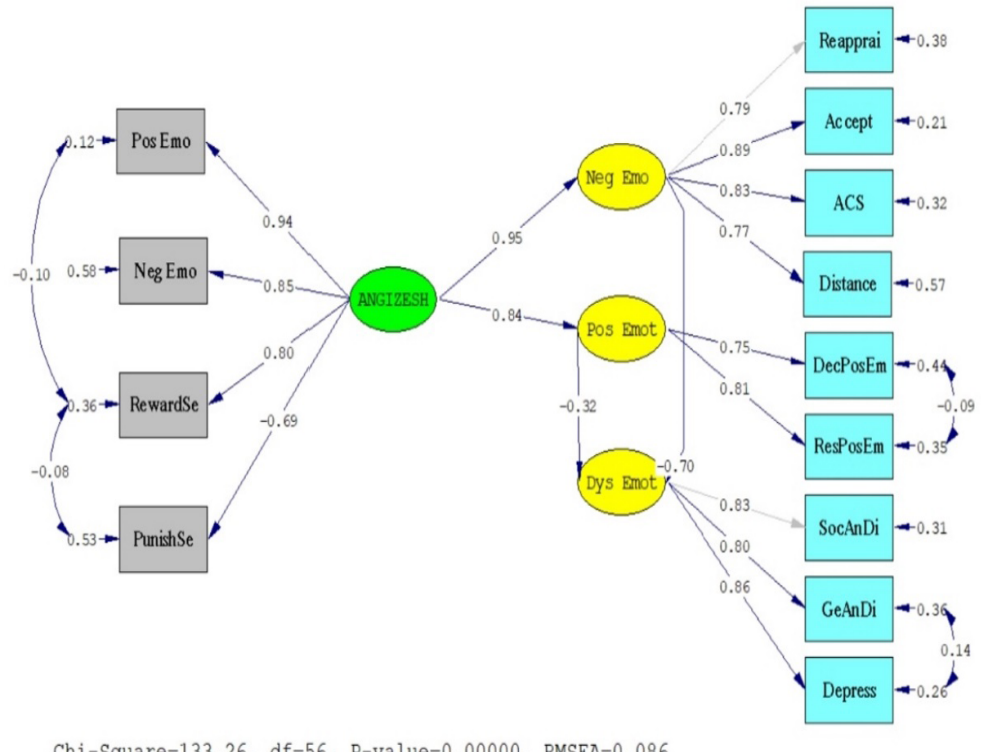

Figure 1. Conceptual model and standardized regression coefficients of the model

Griffiths, Nigro \& Cosenza, 2017; Williams, Grisham, Erskine \& Cassedy, 2012). Another probable reason is that subjects are relatively aware of negative ER. They recognize that these emotions need to be confronted or moderated. However, positive emotions, except in severe cases, do not involve ER and the individual perceives them as natural emotions (Roseman, Spindel \& Jose, 1990).

As mentioned, the current research findings completely supported Mennin's ER model. In the first part of Mennin's model, emotional intensity and punishment, and reward sensitivity are assumed as the factors of overall vulnerability. These variables are expressed under various headings in multiple other models. For example, in the personality traits model (McCrae \& Costa Jr, 1997), the rate of observation and reaction to unpleasant external and internal factors are referred to as neuroticism, i.e., a factor of vulnerability to mood and anxiety disorders. Additionally, in the RST model (Gray \& McNaughton, 2000), BIS and BAS are addressed as two nervous systems that underlie personality and pathology. BIS hyperactivity and low activity of BAS are associated with mental health disorders.

Next, overall vulnerability leads to dysfunctional ERSs. In this case, the results of different studies differed slightly. In the study of Taherifar et al. (2016), the accepting (allowing) ERS played a mediating role more than other strategies; however, the reappraisal strategy presented no significant mediating influence. This finding was consistent with that of the longitudinal study of
Aldao \& Nolen-Hoeksema (2012); they believed that the reappraisal ERS does not predict psychopathological symptoms. However, in general, there is an agreement among researchers that depression is caused by impaired ER (Aldao \& Nolen-Hoeksema, 2012); dysfunctional strategies can also increase the frequency of emotional distress (Purdon, 2004). In this regard, Gross and John's ER model (Gross \& John, 2003) states that functional strategies, like reappraisal, are the protective factors against psychopathology.

The study results are recommended to be considered per its limitations. The first limitation of the present study is attributed ti to the cross-sectional nature of the research. Conducting longitudinal research is critical. This is because some previous longitudinal studies provided different results than the cross-sectional studies. For example, the longitudinal study of Aldao \& Nolen-Hoeksema (2012) signified that the reappraisal ERS does not predict the psychopathological symptoms; however, in most cross-sectional studies, this strategy has been correlated with emotion dysregulation symptoms. Prospective and longitudinal research can be highly beneficial in more precisely evaluating the relationship between the components of the model. The second limitation of the present study was its sample group that makes the results of the present study only generalizable to the student community. To further explore this model, further research is suggested using other healthy samples, such as adolescents and the elderly, or clinical samples, such as those with MDD, GAD, or eating disorders, to reach the purpose of the ER model, i.e., explaining emotional 
disorders and understanding their frequent and trans-diagnostic characteristics. The third limitation of this study was using a questionnaire to diagnose MDD, GAD, and $\mathrm{SAD}$. Subsequent research is recommended to use structured interviews to diagnose these disorders.

\section{Conclusion}

The present study was the first attempt to fully examine the ER model by Mennin et al. (2002). Furthermore, the present study was the first research that examined the impact of positive ERSs along with negative ERSs and the relationship between the two and the mediating role of positive ERSs in the relationship between reward sensitivity and punishment sensitivity, and dysfunctional emotion symptoms. The present study findings completely supported the Mennin model. We revealed that reward and punishment sensitivity and emotion intensity lead to MDD, GAD, and SAD by dysfunctional ERSs.

These findings supported the effectiveness of ER training protocols in various emotion dysregulation symptoms, such as mood disorders and anxiety. Due to the comorbidity of these emotion dysregulation symptoms, teaching therapeutic and preventive ER protocols based on this model (along with expanding or changing some of its components) to therapists and training specialists leads to the treatment of numerous disorders or common pathology components could be found in them. This measure will improve the therapeutic results. Its greater application concerns the healthcare system, and could consequently reduce the economic burden on society.

Due to the staggering cost of mental healthcare services, this approach is extremely useful for treating various common and comorbid disorders. Moreover, the obtained data were consistent with the cognitive-behavioral model; it states that changing one's thoughts and reinterpreting an emotional event is a goal of treating depressive and anxiety disorders (Wang et al., 2019). These results, emphasizing the role of behavioral activation, as a technique that increases reward pursuit by the individual, suggested that this technique can increase rewardseeking; thus, it improves ER (Tugade \& Fredrickson, 2004). Dysfunctional ERSs is modified by cognitivebehavioral therapy which subequently improves the conditions' pathology (Conklin, Morris \& Nolte, 2015). Mindfulness techniques also reduce individiduals' sensitivity to negative events, punishment, and dysfunctional ER (Shapiro, Carlson, Astin \& Freedman, 2006).

\section{Ethical Considerations}

\section{Compliance with ethical guidelines}

There was no ethical consideration to be considered in this research.

\section{Funding}

The paper was extracted from the Ph.D. dissertation of the first author, Department of Education \& Counseling, Central Tehran Branch, Islamic Azad University, Tehran, Iran.

\section{Authors' contributions}

All authors equally contributed to preparing this article.

\section{Conflict of interest}

The authors declared no conflict of interest.

\section{References}

Abasi, I., Feldman, G., Farazmand, Sh., Pourshahbaz, A., \& Sarichloo, M. E. (2018). A psychometric evaluation of Iranian version of the Responses to Positive Affect (RPA) questionnaire. Iranian Journal of Psychiatry and Behavioral Sciences, 12(4), e11923. [DOI:10.5812/ijpbs.11923]

Abasi, I., Mohammadkhani, P., Pourshahbaz, A., \& Dolatshahi, B. (2017). The psychometric properties of attentional control scale and its relationship with symptoms of anxiety and depression: A study on Iranian population. Iranian Journal of Psychiatry, 12(2), 109-17. [PMID] [PMCID]

Abasi, I., Pourshahbaz, A., Mohammadkhani, P., \& Dolatshahi, B. (2017). Mediation role of emotion regulation strategies on the relationship between emotional intensity, safety and reward motivations with social anxiety symptoms, rumination and worry: A structural equation modeling. Iranian Journal of Psychiatry and Behavioral Sciences, 11(3), e9640. [DOI:10.5812/ ijpbs.9640]

Aldao, A., \& Nolen-Hoeksema, S. (2012). When are adaptive strategies most predictive of psychopathology? Journal of Abnormal Psychology, 121(1), 276-81. [DOI:10.1037/a0023598] [PMID]

Balzarotti, S., John, O. P., \& Gross, J. J. (2010). An Italian adaptation of the emotion regulation questionnaire. European Journal of Psychological Assessment, 26(1), 61-7. [DOI:10.1027/10155759/a000009]

Carl, J. R., Gallagher, M. W., \& Barlow, D. H. (2018). Development and preliminary evaluation of a positive emotion regulation augmentation module for anxiety and depression. Be- 
havior Therapy, 49(6), 939-50. [DOI:10.1016/j.beth.2017.11.008] [PMID]

Ciccarelli, M., Griffiths, M. D., Nigro, G., \& Cosenza, M. (2017) Decision making, cognitive distortions and emotional distress: A comparison between pathological gamblers and healthy controls. Journal of Behavior Therapy and Experimental Psychiatry, 54, 204-10. [DOI:10.1016/j.jbtep.2016.08.012] [PMID]

Conklin, A., Morris, Z., \& Nolte, E. (2015). What is the evidence base for public involvement in health-care policy?: Results of a systematic scoping review. Health Expectations, 18(2), 153-65. [DOI:10.1111/hex.12038] [PMID] [PMCID]

Davidson, J. R. T., Hughes, D. L., George, L. K., \& Blazer, D. G. (1993). The epidemiology of social phobia: Findings from the Duke Epidemiological Catchment Area Study. Psychological Medicine, 23(3), 709-18. [DOI:10.1017/s0033291700025484] [PMID]

Dennis, T. A. (2007). Interactions between emotion regulation strategies and affective style: Implications for trait anxiety versus depressed mood. Motivation and Emotion, 31(3), 200-7. [DOI:10.1007/s11031-007-9069-6]

Derryberry, D., \& Reed, M. A. (2002). Anxiety-related attentional biases and their regulation by attentional control. Journal of Abnormal Psychology, 111(2), 225-36. [DOI:10.1037/0021843X.111.2.225] [PMID]

Feldman, G. C., Joormann, J., \& Johnson, Sh. L. (2008). Responses to positive affect: A self-report measure of rumination and dampening. Cognitive Therapy and Research, 32(4), 507. [DOI:10.1007/s10608-006-9083-0] [PMID] [PMCID]

Fresco, D. M., Moore, M. T., van Dulmen, M. H. M., Segal, Z. V., Helen Ma, S., \& Teasdale, J. D., et al. (2007). Initial psychometric properties of the experiences questionnaire: Validation of a self-report measure of decentering. Behavior Therapy, 38(3), 234-46. [DOI:10.1016/j.beth.2006.08.003] [PMID]

Golparvar, M., Javadian, Z., \& Barazandeh, A. (2015). [The relationship between belief in an unjust world and aggressive reaction consider to the interaction function of conscientiousness and cognition (Persian)]. Journal of Psychology, 19(3), 297-313. https://www.sid.ir/fa/journal/ViewPaper. aspx?ID=256467

Goodarzi, M., \& Shameli, L. (2011). [Prediction of identity styles based on sensitivity to reward and punishment (Persian)] Journal of Applied Psychology, 4(4). https:/ / apsy.sbu.ac.ir/article_95200.html

Gratz, K. L., \& Roemer, L. (2004). Multidimensional assessment of emotion regulation and dysregulation: Development, factor structure, and initial validation of the difficulties in emotion regulation scale. Journal of Psychopathology and Behavioral Assessment, 26(1), 41-54. [DOI:10.1023/ B:JOBA.0000007455.08539.94]

Gray, J. A., \& McNaughton, N. (2000). The neuropsychology of anxiety: An enquiry into the functions of the septo-hippocampal system. Oxford: Oxford University Press. https:/ / books.google.com/ books?id=5Nm4jgEACAAJ\&dq

Gross, J. J., \& Jazaieri, H. (2014). Emotion, emotion regulation, and psychopathology: An affective science perspective. Clinical Psychological Science, 2(4), 387-401. [DOI:10.1177/2167702614536164]

Gross, J. J., \& John, O. P. (2003). Individual differences in two emotion regulation processes: Implications for affect, relation- ships, and well-being. Journal of Personality and Social Psychology, 85(2), 348-62. [DOI:10.1037/0022-3514.85.2.348] [PMID]

Huh, H. J., Kim, K. H., Lee, H. K., \& Chae, J. H. (2017). The relationship between childhood trauma and the severity of adulthood depression and anxiety symptoms in a clinical sample: The mediating role of cognitive emotion regulation strategies. Journal of Affective Disorders, 213, 44-50. [DOI:10.1016/j. jad.2017.02.009] [PMID]

Khamseh, M. E., Baradaran, H. R., Javanbakht, A., Mirghorbani, M., Yadollahi, Z., \& Malek, M. (2011). Comparison of the CES$\mathrm{D}$ and $\mathrm{PHQ}-9$ depression scales in people with type 2 diabetes in Tehran, Iran. BMC Psychiatry, 11, 61. [DOI:10.1186/1471244X-11-61] [PMID] [PMCID]

Kline, R. B. (2015). Principles and practice of structural equation modeling. New York, NY: Guilford Press. https://books. google.com/books?id=Q61ECgAAQBAJ\&dq

Kroenke, K., Spitzer, R. L., \& Williams, J. B. W. (2001). The PHQ-9: validity of a brief depression severity measure. Journal of General Internal Medicine, 16(9), 606-13. [DOI:10.1046/ j.1525-1497.2001.016009606.x] [PMID] [PMCID]

Larsen, R. J., \& Diener, E. (1987). Affect intensity as an individual difference characteristic: A review. Journal of Research in Personality, 21(1), 1-39. [DOI:10.1016/0092-6566(87)90023-7]

Mahmoud Alilou, M., Ghasempour, A., Azimi, Z., Akbari, E., \& Fahimi, S. (2012). [Role of emotion regulation strategies in the prediction of borderline personality disorder symptoms (Persian)]. Thought \& Behavior in Clinical Psychology, 6(24), 9-18 https:/ / www.sid.ir/fa/journal/ViewPaper.aspx?ID=215289

Markarian, S. A., Pickett, S. M., Deveson, D. F., \& Kanona, B. B. (2013). A model of BIS/BAS sensitivity, emotion regulation difficulties, and depression, anxiety, and stress symptoms in relation to sleep quality. Psychiatry Research, 210(1), 281-6. [DOI:10.1016/j.psychres.2013.06.004] [PMID]

Mattick, R. P., \& Christopher Clarke, J. (1998). Development and validation of measures of social phobia scrutiny fear and social interaction anxiety. Behaviour Research and Therapy, 36(4), 455-70. [DOI:10.1016/s0005-7967(97)10031-6]

McCrae, R. R., \& Costa Jr, P. T. (1997). Personality trait structure as a human universal. The American Psychologist, 52(5), 509-16. [DOI:10.1037//0003-066x.52.5.509] [PMID]

Mennin, D., \& Farach, F. (2007). Emotion and evolving treatments for adult psychopathology. Clinical Psychology: Science and Practice, 14(4), 329-52. [DOI:10.1111/j.1468-2850.2007.00094.x]

Mennin, D. S., \& Fresco, D. M. (2009). Emotion regulation as an integrative framework for understanding and treating psychopathology. In A. M. Kring, \& D. M. Sloan (Eds.), Emotion regulation and psychopathology: A transdiagnostic approach to etiology and treatment (Pp. 356-379). New York: The Guilford Press. https://books.google.com/books?id=MlRYut8OIMC\&dq

Mennin, D. S., \& Fresco, D. M. (2014). Emotion regulation therapy. In Gross, J. J. (Ed.), Handbook of emotion regulation (Pp. 469490). $2^{\text {nd }}$ Ed. New York: The Guilford Press. https://books. google.com/books?id=_lg1EAAAQBAJ\&dq

Mennin, D. S., Heimberg, R. G., Turk, C. L., \& Fresco, D. M. (2002) Applying an emotion regulation framework to integrative approaches to generalized anxiety disorder. Clinical Psychology: Science and Practice, 9(1), 85-90. [DOI:10.1093/clipsy.9.1.85] 
Mennin, D. S., Heimberg, R. G., Turk, C. L., \& Fresco, D. M. (2005). Preliminary evidence for an emotion dysregulation model of generalized anxiety disorder. Behaviour Research and Therapy, 43(10), 1281-310. [DOI:10.1016/j.brat.2004.08.008] [PMID]

Mennin, D. S., Holaway, R. M., Fresco, D. M., Moore, M. T., \& Heimberg, R. G. (2007). Delineating components of emotion and its dysregulation in anxiety and mood psychopathology. Behavior Therapy, 38(3), 284-302. [DOI:10.1016/j. beth.2006.09.001] [PMID]

Naeinian, M. R., Shaeiri, M. R., Sharif, M., \& Hadian, M. (2011) [To study reliability and validity for a brief measure for assessing Generalized Anxiety Disorder (GAD-7) (Persian)] Clinical Psychology and Personality, 9(1), 41-50. http://cpap. shahed.ac.ir/article_2647.html

Newman, M. G., Przeworski, A., Fisher, A. J., \& Borkovec, T. D. (2010). Diagnostic comorbidity in adults with generalized anxiety disorder: Impact of comorbidity on psychotherapy outcome and impact of psychotherapy on comorbid diagnoses. Behavior Therapy, 41(1), 59-72. [DOI:10.1016/j. beth.2008.12.005] [PMID] [PMCID]

Ohayon, M. M., \& Schatzberg, A. F. (2010). Social phobia and depression: Prevalence and comorbidity. Journal of Psychosomatic Research, 68(3), 235-43. [DOI:10.1016/j.jpsychores.2009.07.018] [PMID]

Ólafsson, R. P., Smári, J., Guðmundsdóttir, F., Ólafsdóttir, G., Harðardóttir, H. L., \& Einarsson, S. M. (2011). Self reported attentional control with the Attentional Control Scale: Factor structure and relationship with symptoms of anxiety and depression. Journal of Anxiety Disorders, 25(6), 777-82. [DOI:10.1016/j.janxdis.2011.03.013] [PMID]

Purdon, Ch. (2004). Empirical investigations of thought suppression in OCD. Journal of Behavior Therapy and Experimental Psychiatry, 35(2), 121-36. [DOI:10.1016/j.jbtep.2004.04.004] [PMID]

Rodebaugh, T. L., Woods, C. M., \& Heimberg, R. G. (2007). The reverse of social anxiety is not always the opposite: The reverse-scored items of the social interaction anxiety scale do not belong. Behavior Therapy, 38(2), 192-206. [DOI:10.1016/j. beth.2006.08.001] [PMID]

Roseman, I. J., Spindel, M. S., \& Jose, P. E. (1990). Appraisals of emotion-eliciting events: Testing a theory of discrete emotions. Journal of Personality and Social Psychology, 59(5), 899-915. [DOI:10.1037/0022-3514.59.5.899]

Shapiro, Sh. L., Carlson, L. E., Astin, J. A., \& Freedman, B. (2006) Mechanisms of mindfulness. Journal of Clinical Psychology, 62(3), 373-86. [DOI:10.1002/jclp.20237] [PMID]

Spitzer, R. L., Kroenke, K., Williams, J. B. W., \& Löwe, B. (2006). A brief measure for assessing generalized anxiety disorder: The GAD-7. Archives of Internal Medicine, 166(10), 1092-7. [DOI:10.1001/archinte.166.10.1092] [PMID]

Taherifar, Z., Ferdowsi, S., Mootabi, F., Mazaheri, M. A., \& Fata, L. (2016). [The mediating role of emotion dysregulation strategies on the relationship between negative emotion intensity and safety motivation with generalized anxiety symptoms (Persian)]. Contemporary Psychology, 10(2), 51-66. http://bjcp. ir/browse.php?a_id=898\&sid=1\&slc_lang=fa
Tavoli, A., Allahyari, A. A., Azadfallah, P., Fathi Ashtiani, A Melyani, M., \& Sahragard, M. (2012). [Validity and reliability of the Farsi version of Social Interaction Anxiety Scale(SIAS) (Persian)]. Iranian Journal of Psychiatry \& Clinical Psychology, 18(3). 227-32. http://ijpcp.iums.ac.ir/article-1-1888-en.html

Torrubia, R., \& Tobeña, A. (1984). A scale for the assessment of 'susceptibility to punishment' as a measure of anxiety: Preliminary results. Personality and Individual Differences, 5(3), 371-5. [DOI:10.1016/0191-8869(84)90078-3]

Tugade, M. M., \& Fredrickson, B. L. (2004). Resilient individuals use positive emotions to bounce back from negative emotional experiences. Journal of Personality and Social Psychology, 86(2), 320-33. [DOI:10.1037/0022-3514.86.2.320] [PMID] [PMCID]

Turk, C. L., Heimberg, R. G., Luterek, J. A., Mennin, D. S., \& Fresco, D. M. (2005). Emotion dysregulation in generalized anxiety disorder: A comparison with social anxiety disorder. Cognitive Therapy and Research, 29(1), 89-106. [DOI:10.1007/ s10608-005-1651-1]

Wang, X., Zhang, R., Chen, X., Liu, K., Wang, L., \& Zhang, J., et al. (2019). Psychopathological correlates and emotion regulation as mediators of approach and avoidance motivation in a Chinese military sample. Frontiers in Psychiatry, 10, 149 [DOI:10.3389/fpsyt.2019.00149] [PMID] [PMCID]

Williams, A. D., Grisham, J. R., Erskine, A., \& Cassedy, E. (2012) Deficits in emotion regulation associated with pathological gambling. British Journal of Clinical Psychology, 51(2), 223-38. [DOI:10.1111/j.2044-8260.2011.02022.x] [PMID] 